\title{
El privilegio de ser titular de derechos humanos
}

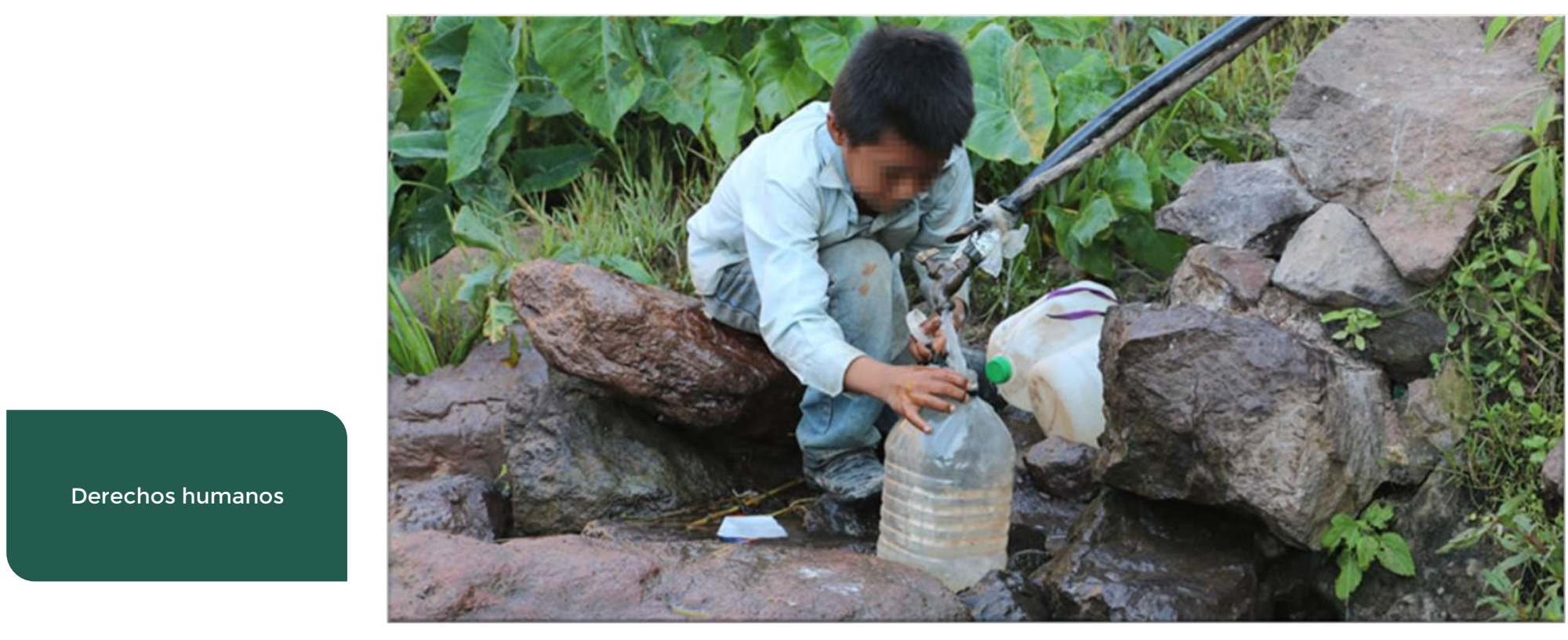

Cuando leemos o escuchamos sobre derechos humanos, por lo general pensamos que no es un tema tan relacionado con nosotros;

que tiene que ver más con países en guerra, con hambruna, con poblaciones tradicionalmente discriminadas o con desplazamientos forzados internos que, si bien nos conmueven, poco afectan nuestra cotidianidad. Sin embargo, esa idea surge justamente del entorno privilegiado en el que nos encontramos. Desde que nacemos tenemos garantizados ciertos derechos que damos por descontados $y$, por tanto, es muy extraña la circunstancia en la que nos tomamos un momento para reflexionar acerca de su verdadero ejercicio y de lo que significa ser titular de todos y cada uno de ellos.

En la actualidad, y en nuestro contexto, si nacemos hombres o mujeres tenemos los mismos derechos a la vida, la educación y el trabajo sin que tengamos que tomar las calles o dar nuestra vida para exigirlo; si somos trabajadores, no debemos luchar porque nuestras jornadas sean de un máximo de ocho horas; si en nuestras casas no se puede pagar un colegio privado, está la posibilidad de estudiar en uno público $y$, en México, incluso se puede ser profesional de una de las mejores universidades de Latinoamérica si acaso es el estudio nuestro interés; si queremos bañarnos, cocinar, lavar ropa o tomar agua, basta con abrir la llave o, en su defecto, pedir un garrafón de agua y se resuelve todo. 
PERSPECTIVAS IMTA

$N^{\circ} .6,2020$

Sin embargo, esta realidad, para muchos de nosotros tan cercana, está muy lejana aún en muchos países del mundo, en donde la falta de acceso al agua o a su saneamiento sigue siendo una de las principales causas de muerte (puede transmitir enfermedades como diarrea, cólera, disentería, fiebre tifoidea y poliomielitis); se calcula que la contaminación del agua potable provoca más de 502,000 muertes por diarrea al año (1). En 2016, la segunda causa de muerte en países de bajos ingresos fue la enfermedad diarreica (2), mientras que, en el mismo año, en los países de ingresos medios fue la sexta causa, y en los países de ingresos altos no aparece en los diez primeros lugares; además, sigue siendo una de las principales causas de muerte entre los menores de cinco años en el mundo (3).

Frente a esta situación, en 2002, mediante la Observación General Núm. 15 de la ONU, el Comité de Derechos Económicos, Sociales y Culturales reconoce el derecho al agua, y en 2010, la ONU define los derechos humanos al agua y al saneamiento (DHAS) como fundamentales para la realización de todos los derechos humanos. En México, la Constitución Política de los Estados Unidos Mexicanos reconoce Ios DHAS a partir de la reforma de 2012 (Art. 4), lo cual ha servido a muchos colectivos, comunidades y organizaciones como argumento que sustente la lucha que por décadas han liderado para que haya agua en sus comunidades.

Sin embargo, este reconocimiento internacional y constitucional no es suficiente para hacer de los DHAS una realidad para todos. Según cifras oficiales del Inegi, derivadas de la Encuesta Nacional de los Hogares, 2016, más de dos millones de hogares carecen de agua en sus casas y más de ocho millones de hogares la reciben de forma intermitente (entre una y tres veces por semana); si consideramos un promedio de cuatro personas por hogar, tenemos que más de cuarenta millones de personas en México no cuentan con agua en sus casas o no la tienen de manera continua, lo cual, además de reflejar una profunda crisis de cumplimiento de los derechos humanos en el país, refleja también una profunda desigualdad invisibilizada por cifras que nos hablan de obras de infraestructura que se ejecutaron sin considerar un enfoque de derechos humanos en su planeación.

Entonces, ¿de qué hablamos cuando decimos que la planeación del sector hídrico debe tener un enfoque de derechos? Hablamos del imperativo ético de pensar en cada una de las personas que se invisibilizan tras la cifra de cuarenta millones o del 33 por ciento y de considerar que con la falta de acceso al agua se están limitando sus derechos a la salud, a un medio ambiente sano, a una vivienda digna, a la igualdad, a la seguridad, a la alimentación, a servicios sociales básicos, en fin, a la vida y a la dignidad. Este es el enfoque del Instituto Mexicano de Tecnología del Agua, trascender el enfoque de costo-beneficio y priorizar sus acciones desde una perspectiva ética, de derechos humanos y del bien común.

https://www.who.int/es/news-room/fact-sheets/detail/drinking-water

https://www.who.int/es/news-room/fact-sheets/detail/the-top-10-causes-of-death

https://www.who.int/elena/titles/wsh_diarrhoea/es/ 